\title{
Additive partitioning of estuarine benthic macroinvertebrate diversity across multiple spatial scales
}

\author{
Alf B. Josefson* \\ National Environmental Research Institute, Aarhus University, Frederiksborgvej 399, 4000 Roskilde, Denmark
}

\begin{abstract}
Knowledge of how diversity changes across spatial scales is important for conservation of biodiversity. Alpha $(\alpha)$, beta $(\beta)$ and gamma $(\gamma)$ species richness and Shannon-Wiener diversity index $\left(H^{\prime}\right)$ of benthic macroinvertebrates were analysed by additive partitioning across 3 different nested spatial scales (cm, m and km scales) in the estuarine Baltic Sea-North Sea transition area. The data set consisted of abundance of 324 species from a total of 638 samples taken at 64 sites distributed over 6 salinity-defined regions. Results were compared to a null model, randomly assigning individuals of species among samples. $\beta$-richness among regions was significantly high and the major contributor to $\gamma$-richness, while $\alpha$ - and $\beta$-richness were less than expected at finer scales, suggesting that salinity-defined regions largely determined $\gamma$-richness. Salinity effects on $\alpha$-richness were positive and most evident at a regional scale, likely reflecting differential evolutionary adaptation to salinity among species. For $H^{\prime}$, the greatest contribution to $\gamma$-diversity was from $\alpha$ and $\beta$ at the finest scale, but significantly high contributions at larger scales likely indicated that different species dominated abundance in different sites and regions. Effects of rare species on partitioning of total richness was less different from random, compared to common species, for $\beta$ among regions, suggesting that the occurrence of rare species was more affected by chance than for common species. Results suggest that additive partitioning is a simple and effective tool to unravel changes and sources in diversity over spatial scales in marine and/or estuarine benthic environments. This method may be used to assess effects of habitat homogenisation and as a basis for the design of conservation protocols.
\end{abstract}

KEY WORDS: Additive partitioning $\cdot \alpha$-diversity $\cdot \beta$-diversity $\cdot \gamma$-diversity $\cdot$ Species richness Rare species $\cdot$ Macroinvertebrates $\cdot$ Salinity

\section{INTRODUCTION}

Biodiversity is generated by various factors operating at various scales (Wiens 1989, Willis \& Whittaker 2002) and is therefore scale-dependent, and this is also true in marine sedimentary habitats (e.g. Hewitt et al. 1998, Ellingsen 2001). For instance, competition occurs among individuals and may therefore be more evident at fine spatial scales, while evolutionary history or dispersal may be more important at larger scales (e.g. Huston 1999). Therefore, in order to give a comprehensive description of diversity and its sources, it is desirable to study diversity components at multiple scales (Loreau 2000). Knowledge of how diversity changes across spatial scales and of the processes behind these changes is important for conservation of biodiversity, because it will allow us to design optimal protocols to measure diversity loss which may have negative effects on ecosystem functioning (Loreau et al. 2001, Solan et al. 2004). For example, if bioturbating species are lost, benthic remineralisation rates may be altered (Lohrer et al. 2004), or if habitat-forming species are removed, species richness will decrease (Thrush et al. 2006).

A means of investigating changes in diversity across scales is additive partitioning of diversity (Lande 1996). Although diversity partitioning dates back to MacArthur et al. (1966) (Veech et al. 2002), the approach 
where total diversity $(\gamma)$ is broken up into additive parts of within-sample $(\alpha)$ and among-samples ( $\beta$ ) diversity at lower spatial hierarchical levels was first used by Lande (1996). He showed that, mathematically, additive partitioning was feasible when concavity was present, i.e. when the sum of average diversities at smaller scales did not exceed diversity at the largest scale. Additive partitioning of diversity is particularly appropriate for studying how $\beta$ changes over spatial scales and for identifying the scale that is most important in generating diversity such as species richness (Lande 1996, Gering et al. 2003). Crist et al. (2003) developed methods for statistical testing of additive partitioning of diversity and detecting sources of variability in diversity.

The approach has, in recent years, been applied to several terrestrial communities such as plants (Wagner et al. 2000, Fournier \& Loreau 2001, Gabriel et al. 2006), insects (Fleishman et al. 2003, Gering et al. 2003, Summerville et al. 2003, Lindo \& Winchester 2008) and birds (Fleishman et al. 2003, Veech \& Crist 2007a) and some freshwater systems (e.g. Stendera \& Johnson 2005). However, to date there are few applications of this method to marine and/or estuarine benthic invertebrate fauna.

Estuaries are transition zones between terrestrial and marine aquatic areas, which are important for instance due to their high productivity (Levin et al. 2001). They are, however, characterised by moderate levels of diversity and, given a strong relationship between diversity and function (e.g. Loreau et al. 2001, Solan et al. 2004), the redundancy in terms of function is likely to be less here, and the loss of species in these environments is thus likely to have serious consequences (Levin et al. 2001). Therefore, protection and maintenance of diversity in estuaries is important. In the present study, additive partitioning of diversity was applied to benthic invertebrate macrofauna in an estuarine area of NW Europe, the North Sea-Baltic Sea transition area, with the specific objective to investigate the importance of salinity on benthic diversity across different spatial scales. Although the general perception is that salinity is a major determinant of diversity in estuaries (Remane 1934, Bonsdorff \& Pearson 1999, Attrill 2002, Attrill \& Rundle 2002, Zettler et al. 2007), little is known about how its effects relate to spatial scales or how different diversity components, e.g. $\alpha$ - and $\beta$-richness or evenness, are affected.

A further issue addressed in the present study is how diversity changes across scales of species categories with different abundance and occupancy in the samples. Communities in soft sediments are often characterised by a great number of rare species, i.e. species that occur in few samples or in low numbers (e.g. Gray et al. 2005). The reason for rareness of a specific spe- cies is seldom is known and the importance of rare species in marine benthic systems has been a recent concern (Gray et al. 2005, Ellingsen et al. 2007, Fontana et al. 2008). Therefore, the additive partitioning approach was applied to the fauna with and without rare species in order to assess influence of rare species on partitions of the total community.

The following hypotheses were addressed:

(1) Null hypothesis: $\alpha$ - and $\beta$-diversity at 3 hierarchical levels - sample (cm scale), site (m scale) and region ( $\mathrm{km}$ scale) - were obtained by random distribution of individuals among samples at the finest scale;

(2) Patterns of $\alpha$ - and $\beta$-diversity are related to differences in large-scale environmental characteristics, specifically salinity or sediment texture;

(3) Patterns of $\alpha$ - and $\beta$-diversity of rare and common species change in a similar way across scales; and

(4) Patterns of $\alpha$ - and $\beta$-diversity are similar among the 3 major taxonomic groups: Polychaeta, Mollusca and Crustacea.

\section{MATERIALS AND METHODS}

Study area and sampling design. The area of study (Fig. 1) comprised a major part of the Kattegat, the Sound and the southwestern Baltic Sea south of Sweden and Denmark, and extended over more than $250 \mathrm{~km}$. The area is microtidal, with irregular changes in water levels due to high and low pressure forcing. Bottom water salinity over the study area varied from $>30 \mathrm{psu}$ in the northern area to around $10 \mathrm{psu}$ in the Baltic Sea area (Table 1). The deeper areas (6 to $30 \mathrm{~m}$ ) are separated from the Baltic Sea by the Drogden Sill in the Sound between Denmark and Sweden, and the water masses north of this sill are salinity-stratified during a large part of the year (Richardson \& Christoffersen 1991, Rasmussen 1994). Water with lower salinity, mostly coming from the Baltic Sea, overlays the more saline water with a halocline at ca. $15 \mathrm{~m}$ water depth.

Fauna. Using the Danish environmental database DNAMAP, a database including environmental and faunal data collected by Danish local and regional authorities, invertebrate fauna data were selected from a total of 64 sites distributed as evenly as possible within each of 6 regions (Fig. 1, Table 1). From each site, usually visited once a year in April-June, 1 sample with 10 replicate core samples was taken. The samples were chosen from years as close together as possible. Of the 64 sites, 43 were visited in 1994 and most of the remaining sites in 1990. The replicate cores were taken with a Haps sampler (Kanneworff \& Nicolaisen 1973) and each covered a bottom area of $0.0143 \mathrm{~m}^{2}$ penetrated to ca. $15 \mathrm{~cm}$ in the sediment. The replicates were 


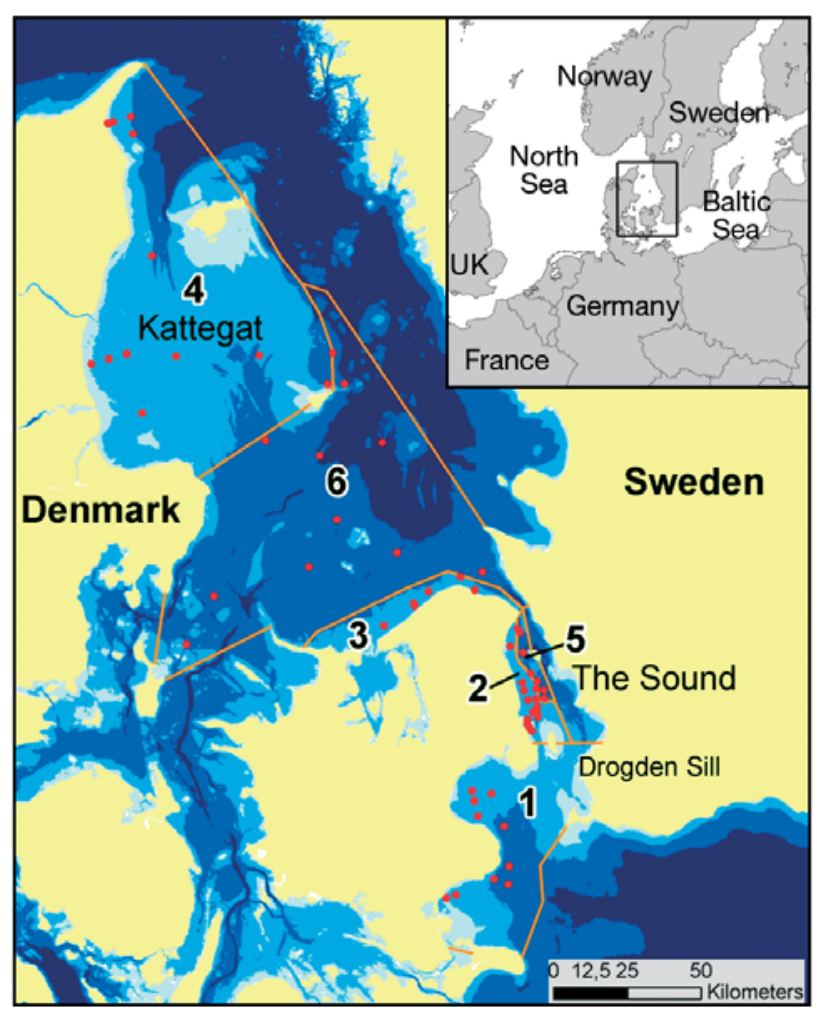

Fig. 1. Study area showing delineations of water mass-defined regions (orange borders) and positions of sites (red dots). Depth zones are indicated by blue shading, from light to dark in the following order: $<5,5$ to 15,15 to 30 and $>30 \mathrm{~m}$. The regions (ID numbers in black) were (1) Baltic Sea; (2) The Sound,

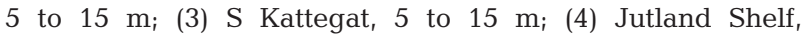
5 to $15 \mathrm{~m}_{i}(5)$ The Sound, $>15 \mathrm{~m}_{i}$ and (6) Kattegat, $>15 \mathrm{~m}$

taken at random, mostly within an area of ca. $25 \times 25 \mathrm{~m}$ at each site. The total area of the samples within each region varied between 1 and $2 \mathrm{~m}^{2}$ (Table 1). The resulting hierarchical data set consisted of 638 samples nested within sites nested within regions. From each sample, data were selected on species abundances of the 3 major taxonomic macroinvertebrate groups: Polychaeta, Mollusca and Crustacea. These 3 groups were each consistently determined to the lowest possible taxon, i.e. mostly to species level, and comprised a major part (often $>90 \%$ of species and individuals) of the fauna in the samples. The fauna material were extracted from the sediment using $1 \mathrm{~mm}$ sieves and otherwise treated following standard methods of preservation and determination of sediment macroinvertebrate fauna (Josefson \& Hansen 2004).

Additive partitioning. According to the concept of additive partitioning (Lande 1996), the diversity in an area based on samples $(\gamma)$ equals the sum of the average diversity within the sample $(\alpha)$ and the average diversity among the samples $(\beta)$, so that $\gamma=\alpha+\beta$, and $\beta$ consequently is given by $\gamma-\alpha$ (Crist et al. 2003). The additive view of $\beta$ allows partitioning of total diversity into $\alpha$ - and $\beta$-diversity at several different nested scales. The application of additive partitioning into $\alpha$ and $\beta$-diversity on the present material allows partitioning of total estuarine diversity into 3 hierarchical spatial levels: the sample unit, the site and the salinitydefined region (Fig. 2).

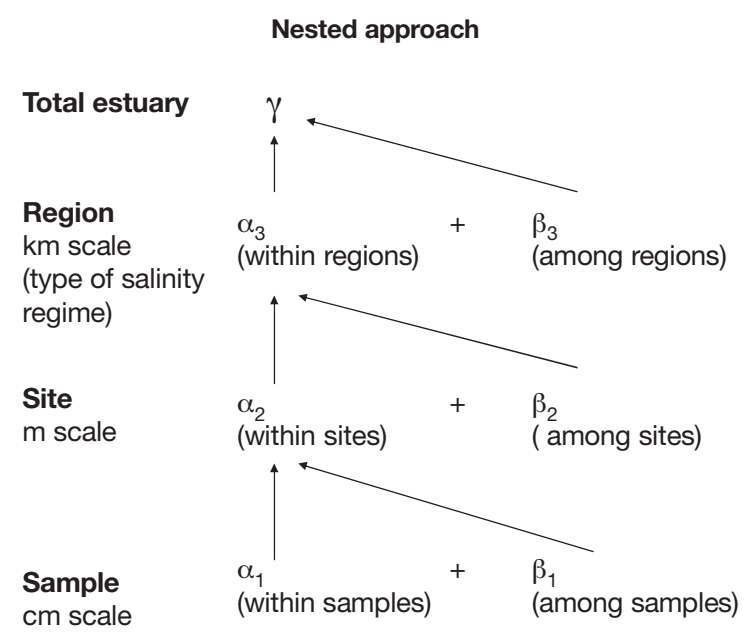

Fig. 2. Scheme of the additive partitioning sampling protocol. $\gamma$ : gamma diversity; $\alpha$ : alpha; $\beta$ : beta. By substitution, the overall diversity is described by: $\gamma=\alpha_{1 \text { within-sample }}+\beta_{1 \text { among samples }}+$ $\beta_{2 \text { among sites }}+\beta_{3 \text { among regions }}$

Table 1. Summary data, including size, depth, salinity from bottom water and sediment texture for each of the 6 regions

\begin{tabular}{|c|c|c|c|c|c|c|c|c|c|}
\hline \multirow[t]{2}{*}{$\begin{array}{l}\text { Region } \\
\text { (km scale) }\end{array}$} & \multirow[t]{2}{*}{$\begin{array}{l}\text { Region size } \\
\quad\left(\mathrm{km}^{2}\right)\end{array}$} & \multirow[t]{2}{*}{$\begin{array}{c}\text { Water } \\
\text { depth (m) }\end{array}$} & \multicolumn{2}{|c|}{$\begin{array}{l}\text { Bottom water } \\
\text { salinity }\end{array}$} & \multirow{2}{*}{$\begin{array}{c}\text { No. of } \\
\text { sites } \\
\text { (m scale) }\end{array}$} & \multirow{2}{*}{$\begin{array}{c}\text { No. of } \\
\text { samples } \\
\text { (cm scale) }\end{array}$} & \multicolumn{2}{|c|}{$\begin{array}{l}\text { Sediment texture } \\
\text { (no. of sites) }\end{array}$} & \multirow[t]{2}{*}{$\begin{array}{l}\text { Sampled } \\
\text { area }\left(\mathrm{m}^{2}\right)\end{array}$} \\
\hline & & & Mean & $\mathrm{SD}$ & & & Sand & Mud & \\
\hline 1. Baltic Sea & 1700 & $5-30$ & 12.04 & 1.19 & 10 & 99 & 4 & 6 & 1.42 \\
\hline 2. The Sound & 238 & $5-15$ & 21.18 & 3.18 & 14 & 140 & 10 & 4 & 2 \\
\hline 3. S Kattegat & 389 & $5-15$ & 22.4 & 1.17 & 7 & 70 & 7 & 0 & 1 \\
\hline 4. Jutland Shelf & 4680 & $5-15$ & 26.86 & 1.36 & 13 & 130 & 8 & 5 & 1.86 \\
\hline 5. The Sound & 103 & $>15$ & 28.67 & 1.8 & 8 & 80 & 1 & 7 & 1.14 \\
\hline 6. Kattegat & 4816 & $>15$ & 32.07 & 0.9 & 12 & 119 & 7 & 5 & 1.7 \\
\hline Total & & & & & 64 & 638 & & & \\
\hline
\end{tabular}


Partitioning was performed on 2 different diversity measures, both fulfilling the criterion of concavity which requires that $\gamma \geq \alpha$ (Lande 1996): species richness (number of species) and the Shannon-Wiener diversity index $\left(H^{\prime}\right)$. It was expected that these 2 measures would generate different partitions as they measure different aspects of the community. Richness gives equal weight to all species, while $H^{\prime}$ gives equal weight to dominance or evenness and species richness, and consequently is much more influenced by diversity of the more abundant species.

Additive partitioning was performed on the total fauna (sum of the 3 major taxonomic groups) and on different selections of species, using the computer program PARTITION (Veech \& Crist 2007b). The program was used for statistical testing of level-specific $\alpha$ and $\beta$ estimates against a null model using a randomization procedure (Crist et al. 2003).

Since the focus here was on the presence of patterns of aggregation that could be related to salinity regimes, the complete unrestricted individual-based randomization approach was used. In brief, null distributions of the diversity measures at all hierarchical levels were created by randomly assigning the individuals among samples at the lowest level (finest scale) (Crist et al. 2003) and repeating this at least 999 times, at the same time preserving the original number of individuals per species and number of individuals per sample (sample size distribution). The observed diversity values were then compared to the null distributions; for example, if $<5 \%$ of the distribution values were above the observed value, the value was considered significantly high at the $5 \%$ level. Similarly, if $>95 \%$ of the null distribution values were above the observed value, it was considered significantly low at the $5 \%$ level.

Patterns of $\alpha$ - and $\beta$-diversity. Differences in largescale environmental characteristics: Since the dependence of salinity effects on scale was part of the hypotheses, the grain of the largest scale was set to water mass-defined regions with more than $10 \mathrm{~km}$ extension. Contiguous bottom areas from 5 to $15 \mathrm{~m}$ depth and deeper than $15 \mathrm{~m}$ along the Kattegat-Sound-Baltic Sea transect formed 6 regions with different salinity regimes (Fig. 1, Table 1). The borders among these regions were more or less distinct because of the (often strong) vertical salinity stratification in the area (e.g. Richardson \& Christoffersen 1991).

Sediment texture information at the sites was obtained from the Areal Information System (AIS) database (Danmarks digitale Havbundstypekort 1:500 000, Geological Survey of Denmark and Greenland) where station positions were matched with sediment characterisation using GIS methods. The sites were classified as either mud (mud or sandy mud) or sand (sand or coarser sediments) (Table 1). Region 3 was the most sandy since all sites were classified as sandy, and Region 5 was the most muddy with only 1 site classified as sandy. The remaining regions contained several sites from each sediment category.

Differences in sediment texture likely reflect differences in habitat, and therefore could affect $\beta$-diversity between regions if there were regional differences in texture. In order to evaluate the importance of sediment texture as a source of variability in diversity at the largest scale, the partitions were performed separately on the 4 regions with a more balanced composition of muddy and sandy sites, i.e. Regions 1, 2, 4 and 6 (Table 1), excluding the most sandy (3) and most muddy (5) regions.

In order to investigate how richness developed in relation to salinity across scales, $\alpha_{1}, \alpha_{2}$ and $\alpha_{3}$ (as defined in Fig. 2) were regressed against mean salinity within the regions.

Rare and common species: Since there is no consensus how to define rareness or commonness, both entities being relative, rare species were categorised in 2 different ways: (1) by total abundance and (2) by occupancy in the samples. Rare species defined by abundance were those that comprised $<0.05 \%$ of the total number of individuals ( $<20$ individuals), following the definition used by Gering et al. (2003) on arboreal Coleoptera, who used a similar-sized data set in terms of number of species and proportion of singletons (i.e. species occurring with only 1 individual). The remaining species thus were more common. Rare species defined by occupancy in the samples were those occurring in $<1 \%$ of the 638 samples, i.e. in $<7$ samples. Partitions were conducted on species richness and $H^{\prime}$ on all species and with rare species excluded.

Taxonomic groups: The partitions were also made separately on each of the 3 taxonomic groups, Polychaeta, Mollusca and Crustacea, for 2 reasons. The first was to evaluate the possible influence of different life-history traits, mainly dispersal modes, on the partitions. Many species of the group Polychaeta have pelagic larval development (Thorson 1946) and are highly motile as adults. Mollusca contain a large fraction of species which disperse via pelagic larvae (Thorson 1946), but adults mostly have restricted motility. Most benthic macrofaunal crustacean species in the Kattegat and the North Sea belong to the order Peracarida, where major groups are Isopoda, Amphipoda and Cumacea, benthic recruiters (e.g. Myers 1997) with brooding and direct development without a pelagic stage (Ruppert \& Barnes 1991). Dispersal by larvae in this group is therefore likely to be restricted; however, several crustacean species are motile as adults. Since pelagic larval dispersal is likely the most effective means of long-distance dispersal, Crustacea is 
expected to be more aggregated at meso- and macroscales than the other 2 groups. The second reason was to contribute to the debate about surrogates in diversity assessments; that is, do the diversity patterns of a single taxonomic group properly reflect the diversity pattern of the total community (e.g. Fleishman et al. 2003, Olsgard et al. 2003)?

\section{RESULTS}

\section{Fauna}

The total data set comprised 41787 individuals and 324 species, of which 75 were singletons (Table 2). The number of species categorised as rare were of similar magnitude between the 2 methods of classification (i.e. by abundance and by occupancy). The most speciesrich group was Polychaeta, followed by Crustacea and Mollusca. Most of the individuals belonged to Polychaeta and Mollusca, and Crustacea had the highest share of singletons (37\%).

\section{Patterns of $\alpha$ - and $\beta$-diversity}

\section{Differences in large-scale environmental characteristics}

The null hypothesis of random distribution among samples could be rejected for both species richness and $H^{\prime}$ at the $5 \%$ level. For richness, the major contribution to $\gamma$-diversity was from $\beta_{3}(>65 \%)$, which was much higher than expected from random. The contributions from $\alpha$ and $\beta$ at finer scales were less than expected from the null model $(\mathrm{p}<0.05)$, in particular $\beta_{1}$ (Fig. 3). For $H^{\prime}$, the major contribution to $\gamma$-diversity was from $\alpha$ at the finest scale (ca. $50 \%$ ) but, similar to richness, was less than expected from random (Fig. 4). The contributions from $\beta_{3}$ and $\beta_{2}$ were much higher than expected from random.

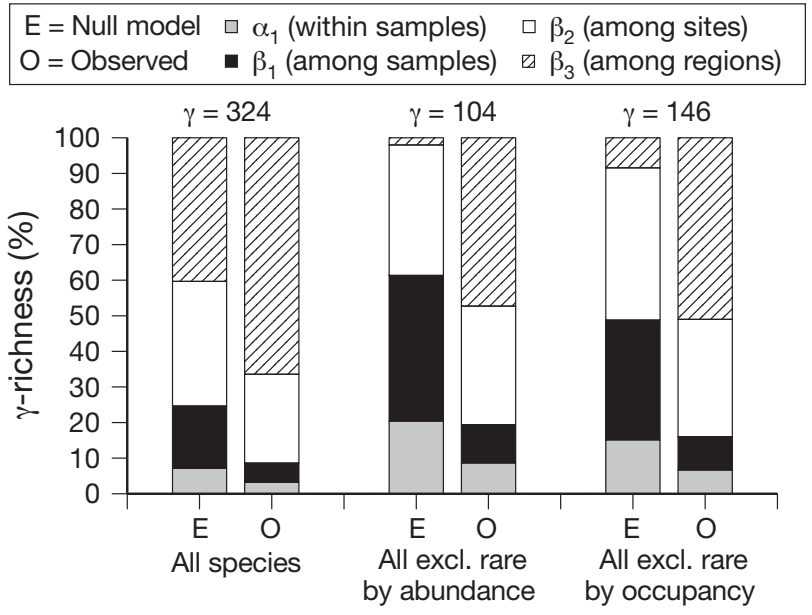

Fig. 3. Percentage of $\gamma$-richness explained by $\alpha$ and $\beta$ components of diversity at 3 spatial scales: core samples, sites and water mass-defined regions. Observed data $(\mathrm{O})$ are compared to expected (E) data from the null model. Results are shown for all species, and after excluding rare species by abundance or by occupancy. In all instances the observed partitions were significantly different $(p<0.05)$ from expectations of the null model

Results of the partitions run separately on regions with both sandy and muddy sediments showed similar results compared to predictions from the null model applied on all regions, with a contribution of $\beta_{3}$ to $\gamma$-diversity around $60 \%$ for richness and ca. $9 \%$ for $H^{\prime}$ (Table 3). Differences in sediment texture do not seem to generate much of the high $\beta_{3}$ observed when partitioning diversity from all regions. The remaining causal factor behind high $\beta_{3}$ is likely differences in water mass properties, most likely salinity. While additive partitioning allows identification of which scale is important for change in diversity, it does not give information on the direction of change versus the environmental factor. The development of $\alpha$ - and $\beta$-richness of the total fauna showed significant increases (Pearson product moment correlation, $\mathrm{p}<0.05$ ) versus bottom water salinity at all scales.
Table 2. Summary data on the fauna for the entire sampling area. Rare species were categorised in 2 ways, by abundance $(<0.05 \%$ of total abundance) and by occupancy $(<1 \%$ of samples). Singletons are species occurring with one individual. $H^{\prime}$ : Shannon-Wiener diversity index

\begin{tabular}{|lcccc|}
\hline Category & $\begin{array}{c}\text { No. of } \\
\text { individuals }\end{array}$ & $\begin{array}{c}\text { No. of } \\
\text { species }\end{array}$ & $\begin{array}{c}\text { No. of } \\
\text { singletons }\end{array}$ & $H^{\prime}$ \\
\hline Total & 41787 & 324 & 75 & 3.38 \\
Rare by abundance & 1084 & 220 & & \\
Rare by occupancy & 561 & 178 & & \\
Polychaeta & 21279 & 151 & 27 & 2.93 \\
Mollusca & 17063 & 80 & 14 & 1.92 \\
Crustacea & 3445 & 93 & 34 & 2.25 \\
\hline
\end{tabular}

Rare and common species

Patterns of $\alpha$ - and $\beta$-diversity of rare and common species did not change in a similar way across scales when partitioning was performed on species richness, although statistical testing showed the same significant signs of deviation from the null model $(\mathrm{p}<0.05)$ at each scale when rare species were excluded as for all species (Fig. 3). Clearly, inclusion of rare species, categorised either 


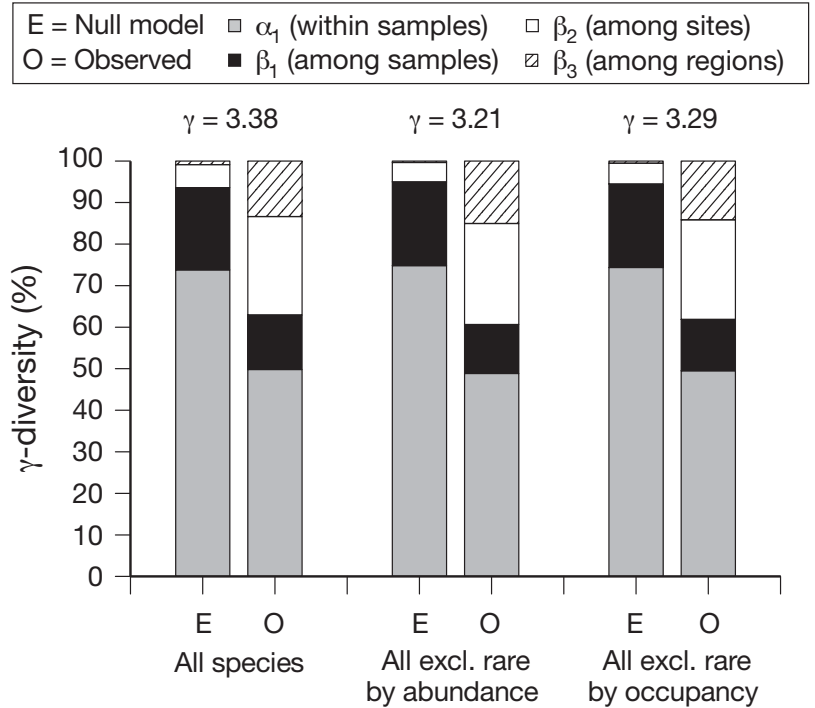

Fig. 4. Percentage of $\gamma$-diversity (Shannon-Wiener diversity index, $H^{\prime}$ ) explained by $\alpha$ and $\beta$ components of diversity at 3 spatial scales: core samples, sites and water mass-defined regions. Observed data $(\mathrm{O})$ are compared to expected $(\mathrm{E})$ data from the null model. Results are shown for all species, and after excluding rare species by abundance or by occupancy. In all instances the observed partitions were significantly different $(\mathrm{p}<0.05)$ from expectations of the null model

Table 3. Results of additive partitioning of $\gamma$-species richness (S) and ShannonWiener diversity index $\left(H^{\prime}\right)$ for all species (total) and by taxonomic group (Polychaeta, Mollusca and Crustacea), sediment texture (Regions 1, 2, 4 and 6) and year (only 1994). Percent contribution of $\alpha$ and $\beta$ to $\gamma$ is given for the null model (Exp) and observed partitions (Obs). Significantly high contributions compared to random $(p<0.05)$ are in bold. The remaining observed values are, with one exception (ns: $p>0.05$ ), significantly low at the $5 \%$ level

\begin{tabular}{|c|c|c|c|c|c|c|c|c|c|}
\hline & $\overline{\operatorname{Exp}}$ & $\alpha_{1}$ & $\overline{\operatorname{Exp}}$ & $\beta_{1}$ & $\overline{\operatorname{Exp}}$ & $\beta_{2}$ & $\overline{\operatorname{Exp}}$ & $\beta_{3}$ & $\gamma$ \\
\hline \multicolumn{10}{|c|}{ Total } \\
\hline $\mathrm{S}$ & 7.1 & 3.2 & 17.5 & 5.4 & 35 & 25 & 40.3 & 66.4 & 324 \\
\hline$H^{\prime}$ & 73.8 & 49.8 & 19.8 & 13.1 & 5.5 & 23.7 & 0.9 & 13.4 & 3.38 \\
\hline \multicolumn{10}{|c|}{ Polychaeta } \\
\hline $\mathrm{S}$ & 8.1 & 3.9 & 19.3 & 6.3 & 35.8 & 26.4 & 36.8 & 63.4 & 151 \\
\hline$H^{\prime}$ & 65.5 & 43.7 & 26 & 15.6 & 7.5 & 24 & 1 & 16.6 & 2.93 \\
\hline \multicolumn{10}{|c|}{ Mollusca } \\
\hline $\mathrm{S}$ & 7.8 & 3.9 & 16.4 & 6.4 & 37.8 & 27.6 & 38.1 & 62.1 & 80 \\
\hline$H^{\prime}$ & 54.9 & 38 & 20.6 & $25.6^{\mathrm{ns}}$ & 23 & 33.3 & 1.4 & 3.1 & 1.92 \\
\hline \multicolumn{10}{|c|}{ Crustacea } \\
\hline $\mathrm{S}$ & 2.9 & 1.3 & 10.4 & 3.3 & 36.1 & 20.3 & 50.5 & 75.1 & 93 \\
\hline$H^{\prime}$ & 25.8 & 14.3 & 31.8 & 22.2 & 38.2 & 27.7 & 4.2 & 35.8 & 2.25 \\
\hline \multicolumn{10}{|c|}{ Sediment texture } \\
\hline $\mathrm{S}$ & 7.8 & 3.6 & 18.6 & 5.9 & 40.4 & 30.5 & 33.1 & 60.1 & 295 \\
\hline$H^{\prime}$ & 76.7 & 52.4 & 17.7 & 13.2 & 5.1 & 25.8 & 0.6 & 8.7 & 3.22 \\
\hline \multicolumn{10}{|l|}{ Year } \\
\hline $\mathrm{S}$ & 8.5 & 3.6 & 19.8 & 6.2 & 31.1 & 21.8 & 40.6 & 68.2 & 279 \\
\hline$H^{\prime}$ & 76.2 & 50.5 & 18.4 & 12.3 & 4.45 & 18.9 & 1.1 & 18.4 & 3.37 \\
\hline
\end{tabular}

by abundance or occupancy, decreased the deviation from the null model for partitions using all species, in particular at the largest scale, $\beta_{3}$ (Fig. 3). This implies that the more common species are more aggregated into regions than rare species, and that rare species occurrence is more affected by chance than richness of common species.

The partitions of $H^{\prime}$ were only slightly affected by exclusion of rare species (Fig. 4).

\section{Taxonomic groups}

Partitioning of total species richness for each taxonomic group (Table 3 ) generally showed a very high contribution, 62 to $75 \%$, by $\beta$ among regions, and this was significantly higher $(\mathrm{p}<0.05)$ than expected from the random model (Table 3 ). At the same time, richness at the finer scales, in particular $\alpha_{1}$ and $\beta_{1}$, were significantly lower $(\mathrm{p}<0.05)$ than expected from chance (Table 3$)$. $\beta$-richness among sites $\left(\beta_{2}\right)$, although significantly lower than expected from chance, showed the least difference from expected values for Polychaeta and Mollusca (Table 3). Partitioning and testing against the random model of total $H^{\prime}$ diversity (Table 3) showed a similar result as for richness, in that $\beta_{3}$ was much higher than expected and $\alpha_{1}$ and $\beta_{1}$ were much lower than expected. $\beta_{2}$ values for Polychaeta and Mollusca, however, were significantly higher than expected $(\mathrm{p}<0.05)$, which differed from the results for richness (Table 3 ). The contribution of $\alpha_{1}$ to total diversity was, as expected, much higher for this diversity measure compared to richness.

The development of $\alpha$-richness $\left(\alpha_{1}, \alpha_{2}\right.$ and $\alpha_{3}$ ) versus bottom water salinity at all scales for Polychaeta and the 2 largest scales for Mollusca showed significant increases (Pearson product moment correlation, $\mathrm{p}<0.05)$. The trends for Crustacea were not significant $(\mathrm{p}>$ 0.05), although Pearson $\mathrm{r}$ coefficients were positive at all scales (Fig. 5); the largest scale, region, is represented by total counts and, since sample numbers were different among regions, values obtained by rarefaction are shown for the same sample size (70 samples). The development of $\alpha$-richness versus salinity was, in general, positive, but dependent on scale and taxonomic group, the latter in particular at the finest scales. Thus effects of salinity on richness were most apparent at the largest scale. 


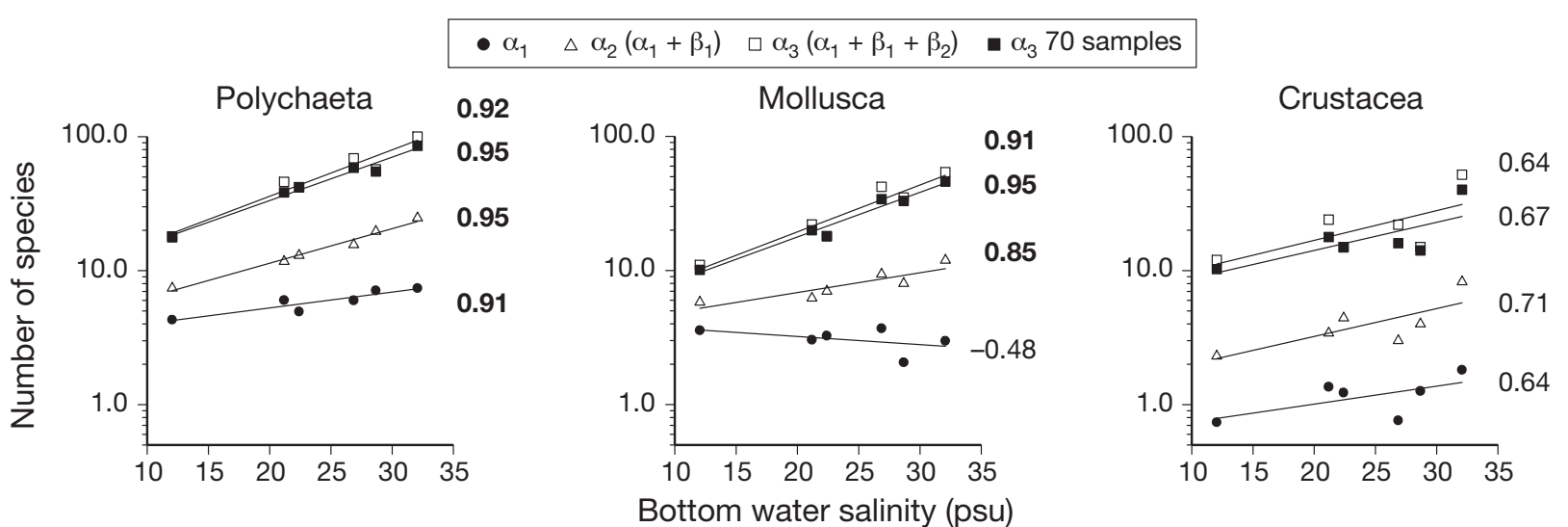

Fig. 5. Plots of average $\alpha_{1}, \alpha_{2}$ and $\alpha_{3}$ species richness of Polychaeta, Mollusca and Crustacea against mean bottom water salinity in the 6 regions. Since the number of samples differed among regions, $\alpha_{3}\left(\alpha_{1}+\beta_{1}+\beta_{2}\right)$ is also given as the number of species in 70 samples from randomised accumulation curves. Pearson's $\mathrm{r}$ coefficients $>0.80$ (in bold) are significant at the $5 \%$ level

\section{DISCUSSION}

The present study was designed to assess the contribution of $\alpha$ and $\beta$, at 3 different spatial scales, to total diversity $(\gamma)$, including the contribution of $\beta$ among different water mass-defined bottom regions to $\gamma$. Additive partitioning allows $\gamma$-diversity to be partitioned on the basis of any categorical factor (such as habitat) and can therefore be used to analyse any postulated determinant of species diversity (Veech et al. 2002). Determination of diversity is highly dependent on sample grain and the extent of study, i.e. areal extent of the area sampled (Crist \& Veech 2006). This is one reason for the statistical testing for significance of the partitions in the present study, since the extent of the regions differed by 1 order of magnitude (Table 1).

Results indicated that the overall null hypothesis must be rejected; diversity patterns in the area were not random. A significant finding was that the largescale $\beta$ component of richness was much greater than expected from random, which indicated that regional factors related to water mass-defined regions structure, in particular, species richness and composition in the area. At the same time, $\alpha$ and $\beta$ at the finer scales were much less than expected from the null model. Thus species were, to a great extent, aggregated into regions. To test if this pattern was mainly influenced by spatial differences, partitions were run only on data from 1994, which resulted in more or less the same result as partitioning the total data set (Table 3). From the development of $\alpha_{3}$ versus salinity, it was apparent that much of the high $\beta_{3}$-richness was due to different levels of richness among regions, where high-saline regions contained more species than regions with lower salinity (Fig. 5).
While $\beta_{3}$ generated by far the greatest contribution to $\gamma$-richness, the $\alpha_{1}$ component determined a large part of $\gamma$-diversity $\left(H^{\prime}\right)$ although less than expected from random. However, the partitions of $H^{\prime}$ suggested a significantly high $(\mathrm{p}<0.05)$ contribution to $\gamma$ by both $\beta_{2}$ and $\beta_{3}$. Since partitioning of richness showed a signficantly low $\beta_{2}$ component, the significantly high $\beta_{2}$ component for $H^{\prime}$ is likely due to additions to the evenness component of $H^{\prime}$, i.e. different species dominating at different sites. Partitioning of this evenness-influenced index thus tells us that the most common and/or dominant species contribute to total diversity over a range of scales.

Sediment structure is known to be important for the distribution of different species (e.g. Gray 2002) and to characterise different habitats. The question then was to what extent the different regions in the present study differed with respect to sediment structure and if this could explain some of the increase in $\beta_{3}$. First, all samples were taken in sedimentary bottoms which allow penetration of the sampling gear to at least $15 \mathrm{~cm}$ depth. This ensured some similarity among sediments in different regions. In general, due to different exposure to waves, sediments at shallower depths are often sandier than sediments at greater depths. One shallow region was primarily sandy and one deep region was primarily muddy. The remaining regions contained both sandy and muddy sites. Since partitions using only the regions with both sediment types showed results similar to partitions using all 6 regions, sediment texture differences were likely of less importance than other factors behind the high $\beta$-diversity among regions. Remaining possibilities for increased $\beta_{3}$, therefore, are differential adaptation of the benthic species to different regional salinity regimes, i.e. high 
niche limitation (e.g. Gaston et al. 2007), or restrictions in dispersal between regions. Since there was no major difference in the partitions among the taxonomic groups with different dispersal modes (planktonic or benthic development) (Table 3), a high niche limitation is more likely the reason for the high $\beta_{3}$. A likely mechanism is evolutionary adaptation to different salinity regimes.

The sea floor is often heterogeneous, or patchy, at different scales, from fine-scale biogenic patches (Hewitt et al. 2005) to benthic landscapes often geophysically formed (Zajac 2008a,b). In estuaries, the presence of water masses with different physicochemical properties, i.e. salinity, is one source of large-scale heterogeneity in species distributions on the bottom (e.g. Attrill \& Rundle 2002). Theoretical work suggests that changed connectivity among patches will differentially affect the $\alpha, \beta$ and $\gamma$ components of richness (Mouquet \& Loreau 2003). Decreased dispersal among patches will increase $\beta$-diversity, and so will high niche specificity (Gaston et al. 2007). For instance, empirical studies in soft-sediment invertebrate communities showed that small-scale shell debris generated patchiness and maintained high $\beta$-diversity (Hewitt et al. 2005). The high contribution of $\beta_{3}$ to $\gamma$-richness in the present study suggests some barriers among regions (e.g. Lindo \& Winchester 2008) which were defined by different water masses. Some previous studies in coastal areas have found high $\beta$-diversity between water masses, in agreement with the present study. Wagner (1999) reported high $\beta$-richness (species turnover) among different water masses in estuarine fish communities on the US east coast, and in the studied area Rosenberg \& Möller (1979) demonstrated a major change in percent similarity based on presence/absence of species between invertebrate communities above and below the halocline at ca. $15 \mathrm{~m}$ depth along the Swedish west coast. There are, however, a few marine benthic studies that document change in $\beta$ over several spatial scales, and most of them found the highest $\beta$ at the finer scales (Hewitt et al. 2005 and references therein).

As in several terrestrial insect communities (e.g. Gering et al. 2003), richness in marine communities is often dominated by rare species (Gray et al. 2005). Addition of rare species, such as singletons, is often the cause behind the continued increase of species-sample accumulation curves. The importance of rare species in marine invertebrate communities has been recently discussed in the literature (e.g. Gray et al. 2005, Ellingsen et al. 2007, Fontana et al. 2008). The occurrence of rare species has been attributed to sampling artefacts, due to extraction methods (Fontana et al. 2008) and/or undersampling of the populations. An additional possibility is that some rare species are 'vagrants'; that is, species accidentally dispersed which do not have viable/reproductive populations in the environment of study. Gray et al. (2005) identified 2 different groups in the log-normal species abundance distributions which they named common and rare species, possibly indicating different functional groups, where the rare species were suggested to be recruited from outside the environment of study. In the present study, when species defined as rare were excluded, the partitions of the remaining species (the more common species) showed a different pattern of species richness compared to partitions of all species in relation to the random model.

$\beta_{3}$-richness including rare species (all species) was significantly high and gave the highest contribution to $\gamma$-richness, but the increase in relation to the null model was modest. However, $\beta_{3}$ for the more common species was also significantly high, and several times higher than predicted. The contributions of $\alpha$ and $\beta$ at the finer scales were significantly low for both all species and when excluding rare species. These results suggest that the more common species were more aggregated into regions than rare species, while rare species abundance deviated less from random. Since regions differed mainly with respect to salinity regimes, this may suggest that salinity affects richness of common species more than richness of rare species. These findings make sense, if common species represent species with viable populations adapted to the salinity regime in the region, and if some of the rare species represent vagrants that may occur in the region by chance. $H^{\prime}$ showed only minor differences between partitions (all species and excluding rare species); this is likely due to the fact that common species determine dominance, an important component of $H^{\prime}$.

Contrary to expectation, there did not seem to be major differences in the partitions of richness among the 3 taxonomic groups, which suggests that dispersal or mobility were overridden by other factors. This may seem contradictory to Josefson \& Hansen (2004), who found different relations among richness in these 3 groups and saltwater flux in Danish estuaries. However, data from the present study comes from an open area with comparatively high water flux rates, where water transport rates are not likely to be limiting for dispersal of pelagic or benthic larvae or even adults. However, there were differences among the 3 groups in the development of $\alpha_{1}, \alpha_{2}$ and $\alpha_{3}$ versus salinity. At the regional scale, there were strong positive relations between $\alpha_{3}$-richness and salinity for Polychaeta and Mollusca and an insignificant positive slope for Crustacea. Whether or not $\alpha$-diversity at the smaller scales, sample $\left(\alpha_{1}\right)$ or site $\left(\alpha_{2}\right)$, were related to salinity was largely dependent on taxonomic group. Site richness $\left(\alpha_{2}\right)$ for Polychaeta and Mollusca was positively related to mean salinity, while this measure for Crustacea was 
not significant. At the finest scale, $\alpha_{1}$, only richness of Polychaeta was related to salinity. These differences suggest that using species richness of either of the groups as a surrogate for each other is dependent on scale.

The weak response to changed salinity at the finest scale is in agreement with Hyland et al. (2004), who studied richness in eastern US estuaries.

The clear results of additive partitioning in the present study, which concur with the current knowledge about the estuarine environment, suggest that additive partitioning is an effective and simple way to assess sources of heterogeneity in diversity in marine and/or estuarine systems. It can give a sound basis for design of conservation actions; for instance, conservation of benthic invertebrate richness in the North Sea-Baltic Sea transition area demands a large-scale approach, with multiple sites within each region. This is because, to a great extent, different species occur in different salinity-defined regions. Additive partitioning could also be used to assess effects of homogenisation of habitats, which has occurred in several marine systems as a consequence of bottom trawling and eutrophication (e.g. Thrush \& Dayton 2002, Thrush et al. 2006). For instance, homogenization by removing habitatforming species may be predicted to decrease the $\beta$ component at finer scales.

Acknowledgements. Thanks go to the local environmental authorities in Denmark for providing much of the data now stored in the DNAMAP database; to the Øresund Consortium for use of hydrographical and faunal data from the Sound; and to C. Göke for the GIS work. The comments from 4 anonymous referees greatly improved the paper. This is a contribution within the MARBEF Network of Excellence 'Marine Biodiversity and Ecosystem Functioning' EU 6th Framework Programme (contract no. GOCE-CT-2003-505446).

\section{LITERATURE CITED}

Attrill MJ (2002) A testable linear model for diversity trends in estuaries. J Anim Ecol 71:262-269

Attrill MJ, Rundle SD (2002) Ecotone or ecocline: ecological boundaries in estuaries. Estuar Coast Shelf Sci 55:929-993

Bonsdorff E, Pearson TH (1999) Variation in the sublittoral macrozoobenthos of the Baltic Sea along environmental gradiens: a functional-group approach. Aust J Ecol 24: 312-326

> Crist TO, Veech JA (2006) Additive partitioning of rarefaction curves and species-area relationships: unifying $\alpha-, \beta$ - and $\gamma$-diversity with sample size and habitat area. Ecol Lett 9:923-932

Crist TO, Veech JA, Gering JC, Summerville KS (2003) Partitioning species diversity across landscapes and regions: a hierarchical analysis of $\alpha, \beta$, and $\gamma$ diversity. Am Nat 162: 734-743

Ellingsen KE (2001) Biodiversity of a continental shelf softsediment macrobenthos community. Mar Ecol Prog Ser 218:1-15
Ellingsen KE, Hewitt JE, Thrush SF (2007) Rare species, habitat diversity and functional redundancy in marine benthos. J Sea Res 58:291-301

> Fleishman E, Betrus CJ, Blair RB (2003) Effects of spatial scale and taxonomic group on partitioning of butterfly and bird diversity in the Great Basin, USA. Landscape Ecol 18: 675-685

Fontana G, Ugland KI, Gray JS, Abbiati M (2008) Influence of rare species on beta diversity estimates in marine benthic assemblages. J Exp Mar Biol Ecol 366:104-108

> Fournier E, Loreau M (2001) Respective roles of recent hedges and forest patch remnants in the maintenance of ground-beetle (Coleoptera: Carabidae) diversity in an agricultural landscape. Landscape Ecol 16:17-32

Gabriel D, Roschewitz I, Tscharntke T, Thies C (2006) Beta diversity at different spatial scales: plant communities in organic and conventional agriculture. Ecol Appl 16: 2011-2021

Gaston KJ, Evans KL, Lennon JJ (2007) The scaling of spatial turnover: pruning the ticket. In: Storch D, Marquet PA, Brown JH (eds) Scaling biodiversity. Cambridge University Press, Cambridge, p 181-222

Gering JC, Crist TO, Veech JA (2003) Additive partitioning of species diversity across multiple scales: implications for regional conservation of biodiversity. Conserv Biol 17: 488-499

> Gray JS (2002) Species richness of marine soft sediments. Mar Ecol Prog Ser 244:285-297

> Gray JS, Bjørgesæeter A, Ugland KI (2005) The impact of rare species on natural assemblages. J Anim Ecol 74: 1131-1139

> Hewitt JE, Thrush SF, Cummings VJ, Turner SJ (1998) The effect of changing sampling scales on our ability to detect effects of large-scale processes on communities. J Exp Mar Biol Ecol 227:251-264

> Hewitt JE, Thrush SF, Halliday J, Duffy C (2005) The importance of small-scale habitat structure for maintaining beta diversity. Ecology 86:1619-1626

> Huston MA (1999) Local processes and regional patterns: appropriate scales for understanding variation in the diversity of plants and animals. Oikos 86:393-401

Hyland JL, Balthis WL, Posey M, Hackney CT, Alphin T (2004) The soft-bottom macrobenthos of North Carolina estuaries. Estuaries 27:501-514

> Josefson AB, Hansen JLS (2004) Species richness of benthic macrofauna in Danish estuaries and coastal areas. Glob Ecol Biogeogr 13:273-288

Kanneworff E, Nicolaisen W (1973) The Haps, a frame-supported bottom corer. Ophelia 10:119-129

> Lande R (1996) Statistics and partitioning of species diversity, and similarity among multiple communities. Oikos 76: $5-13$

> Levin LA, Boesch DF, Covich A, Dahm C and others (2001) The function of marine critical transition zones and the importance of sediment biodiversity. Ecosystems 4: $430-451$

Lindo Z, Winchester NN (2008) Scale dependent diversity patterns in arboreal and terrestrial oribatid mite (Acari: Oribatida) communities. Ecography 31:53-60

Lohrer AM, Thrush SF, Gibbs MM (2004) Bioturbators enhance ecosystem function through complex biogeochemical interactions. Nature 431:1092-1095

$>$ Loreau M (2000) Are communities saturated? On the relationship among $\alpha, \beta$ and $\gamma$ diversity. Ecol Lett 3:73-76

Loreau M, Naeem S, Inchausti P, Bengtsson J and others (2001) Biodiversity and ecosystem functioning: current knowledge and future challenges. Science 294:804-808 
MacArthur R, Recher H, Cody M (1966) On the relation among habitat selection and species diversity. Am Nat 100:319-332

Mouquet N, Loreau M (2003) Community patterns in sourcesink metacommunities. Am Nat 162:544-557

Myers AA (1997) Biogeographic barriers and the development of marine biodiversity. Estuar Coast Shelf Sci 44:241-248

Olsgard F, Brattegard T, Holthe T (2003) Polychaetes as surrogates for marine biodiversity: lower taxonomic resolution and indicator groups. Biodivers Conserv 12:1033-1049

Rasmussen B (1994) Blandningsmekanismer i kystnære farvande. Havforskning fra Miljøstyrelsen, No. 32. Miljøstyrelsen, Copenhagen

Remane A (1934) Die Brackwasserfauna (Mit besonderer Beruecksichtigung der Ostsee). Zool Anz 7(Suppl):34-74

> Richardson K, Christoffersen A (1991) Seasonal distribution and production of phytoplankton in the southern Kattegat. Mar Ecol Prog Ser 78:217-227

Rosenberg R, Möller P (1979) Salinity stratified benthic macrofaunal communities and long-term monitoring along the west coast of Sweden. J Exp Mar Biol Ecol 37: 175-203

Ruppert EE, Barnes RD (1991) Invertebrate zoology, 6th edn. Saunders College Publications, New York

Solan M, Cardinale BJ, Downing AL, Engelhardt KAM, Ruesink JL, Srivastava DS (2004) Extinction and ecosystem function in the marine benthos. Science 306: $1177-1180$

Stendera SES, Johnson RK (2005) Additive partitioning of aquatic invertebrate species diversity across multiple scales. Freshw Biol 50:1360-1375

Summerville KS, Boulware MJ, Veech JA, Crist TO (2003) Spatial variation in species diversity and composition of forest Lepidoptera in eastern deciduous forests of North America. Conserv Biol 17:1045-1057

Submitted: May 2, 2009; Accepted: October 19, 2009
Thorson G (1946) Reproduction and larval development of Danish marine bottom invertebrates. C. A. Reitzels Forlag, Copenhagen

Thrush SF, Dayton PK (2002) Disturbance to marine benthic habitats by trawling and dredging: implications for marine biodiversity. Annu Rev Ecol Syst 33:449-473

$>$ Thrush SF, Gray JS, Hewitt JE, Ugland KI (2006) Predicting the effects of habitat homogenization on marine biodiversity. Ecol Appl 16:1636-1642

Veech JA, Crist TO (2007a) Habitat and climate heterogeneity maintain beta-diversity of birds among landscapes within ecoregions. Glob Ecol Biogeogr 16:650-656

Veech JA, Crist TO (2007b) PARTITION: software for the hierarchical additive partitioning of species diversity, version 2 . Available at: www.users.muohio.edu/cristto/partition.htm

> Veech JA, Summerville KS, Crist TO, Gering JC (2002) The additive partitioning of species diversity: recent revival of an old idea. Oikos 99:3-9

Wagner CM (1999) Expression of the estuarine species minimum in littoral fish assemblages of the lower Chesapeake Bay tributaries. Estuaries 22:304-312

> Wagner HH, Wildi O, Ewal KC (2000) Additive partitioning of plant species diversity in an agricultural mosaic landscape. Landscape Ecol 15:219-227

Wiens JA (1989) Spatial scaling in ecology. Funct Ecol 3: 385-397

> Willis KJ, Whittaker RJ (2002) Species diversity: scale matters. Science 295:1245-1248

Zajac RN (2008a) Macrobenthic diversity and sea floor landscape structure. J Exp Mar Biol Ecol 366:198-203

> Zajac RN (2008b) Challenges in marine, soft-sediment benthoscape ecology. Landscape Ecol 23:7-18

Zettler ML, Schiedek D, Bobertz B (2007) Benthic biodiversity indices versus salinity gradient in the Southern Baltic Sea. Mar Pollut Bull 55:258-270

Proofs received from author(s): November 26, 2009 